\title{
Life cycle inventories of electricity generation and power supply in version 3 of the ecoinvent database-part II: electricity markets
}

\author{
Karin Treyer • Christian Bauer
}

Received: 12 August 2013 / Accepted: 21 December 2013 /Published online: 28 January 2014

(C) Springer-Verlag Berlin Heidelberg 2014

\begin{abstract}
Purpose Representative, consistent and up-to-date life cycle inventories (LCI) of electricity supply are key elements of ecoinvent as an LCI background database since these are often among the determining factors with regard to life cycle assessment (LCA) results. ecoinvent version 3 (ev3) offers new LCI data of power supply (electricity markets) in 71 geographies. This article gives an overview of these electricity markets and discusses new ecoinvent features in the context of power supply.

Methods The annual geography- and technology-specific electricity production for the year 2008 specifies the technology shares on the high-, medium- and low-voltage level electricity markets. Data are based on IEA statistics. Different voltage levels are linked by transformation activities. Regionspecific electricity losses due to power transmission and voltage transformation are considered in the market and transformation activities. The majority of the 71 power markets are defined by national boundaries. The attributional ecoinvent system model in ev3 with linking to average current suppliers results in electricity markets supplied by all geographyspecific power generation technologies and electricity imports, while the consequential system model generates markets only linked to unconstrained suppliers.

Results and discussion The availability of LCI data for 71 electricity markets in ev3 covering 50 countries reduces the "Rest-of-the-World" electricity supply not covered by
\end{abstract}

Responsible editor: Niels Jungbluth

Electronic supplementary material The online version of this article (doi:10.1007/s11367-013-0694-x) contains supplementary material, which is available to authorized users.

K. Treyer $(\bowtie) \cdot$ C. Bauer

Laboratory for Energy Systems Analysis, Paul Scherrer Institut (PSI),

Villigen 5232, Switzerland

e-mail: karin.treyer@psi.ch country- or region-specific inventories to $17 \%$ for the year 2008. Specific power supply activities for all countries contributing more than $1 \%$ to global electricity production are available. The electricity markets show large variations concerning contributions from specific technologies and energy carriers. Imports can substantially change the national/ regional power mix, especially in small markets. Large differences can also be observed between the electricity markets in the attributional and the consequential database calculation. Region-specific total power losses between production on the high voltage level and consumer on the low voltage level are on the order of $2.5-23 \%$.

Conclusions Electricity supply mixes (electricity markets) in the ecoinvent database have been updated and substantially extended for v3. Inventories for electricity supply in all globally important economies are available with geographyspecific technology and market datasets which will contribute to increasing quality and reducing uncertainties in LCA studies worldwide and to allow more accurate estimation of environmental burdens from global production chains. Future work should focus on improving the details of countryspecific data, implementation of more countries into the database, splitting of large countries into smaller regions and on developing a more sophisticated approach specifying countryspecific electricity mixes in consequential system models.

Keywords Country specific $\cdot$ ecoinvent $v 3 \cdot$ Electricity markets $\cdot$ Electricity mix

\section{Introduction}

When performing life cycle assessment (LCA), energy and specifically electricity use is often an important driver of environmental impacts (Bousquin et al. 2012; Heinonen and Junnila 2011; Teehan and Kandlikar 2012; Hischier and 
Baudin 2010; Mohr et al. 2009; Torrellas et al. 2012; Mendoza et al. 2012; Kendall and McPherson 2012; Milà i Canals et al. 2011; Hawkins et al. 2012). International standards such as PAS 2050 (Publicly Available Specification; PAS 2011) and ISO 14040 and 14044 (ISO 2006a, b) emphasise the importance of detailed and accurate electricity data. Consequently, the update and extension of the electricity sector was a core task within the development of ecoinvent version 3 . The new version $\mathrm{v} 3$ of the ecoinvent database contains life cycle inventories (LCI) and life cycle impact assessment (LCIA) results for power supply in 71 geographic regions, i.e. electricity markets, worldwide. All the geographic regions and their corresponding country codes are shown in Table 1 . These electricity markets represent $83 \%$ of global electricity supply in the year 2008; markets for all countries with shares of more than $1 \%$ of global supply as well as some smaller ones are now available. The objective of the work presented in the two papers on electricity in this ecoinvent $\mathrm{v} 3$ special issue is to provide updated and extended LCI of electricity producing technologies (paper part I (Treyer and Bauer 2013)) and electricity markets (paper part II). The content of this paper part II is the presentation and discussion of the LCI data for country- and region-specific electricity markets (supply mixes) on different voltage levels as well as production mixes. Consequences of the different options for linking the unit processes, i.e. the attributional and the consequential system model in ecoinvent $\mathrm{v} 3$ are discussed. The (electricity) market datasets are automatically filled by the software layer of the database using the unit processes (activities) according to specific linking rules for the two different system models. This new linking system of ecoinvent $v 3$ provides advantages which can especially be shown by means of the electricity datasets: Firstly, new electricity production datasets automatically supply the electricity markets of the corresponding geographic region and do not have to be included manually into the electricity market. Secondly, the linking algorithm can be adjusted according to specific goals of an LCA, e.g. attributional or consequential LCA. Depending on the implementation of the new ecoinvent features in LCA software tools, users might be able to adapt the mixes to their own needs. This would allow for adjustment of the marginal electricity mix in the consequential version based on different approaches regarding how the marginal technologies should be identified or which time horizon should be considered, e.g. (Lund et al. 2010; Mathiesen et al. 2009; Schmidt et al. 2011). As a background database, ecoinvent $\mathrm{v} 3$ is the first to provide a consistent approach for filling the gap in LCI data for consequential LCA.

\section{Methods}

All electricity (market) unit process datasets in ecoinvent $\mathrm{v} 3$ have been created according to the ecoinvent Data Quality
Guidelines (DQG) (Weidema et al. 2013). These guidelines give an overview and the methodological background of the database and its new features. The electricity supplying technologies and their modelling in ecoinvent are described in part I of this paper (Treyer and Bauer (2013)). These technologies are represented as follows:

- Coal: hard coal, lignite, peat

- Gases: natural gas (in conventional and combined cycle power plants with and without combined heat and power), blast furnace gas, coal gas

- Oil

- Nuclear: pressurised/boiling water reactor

- Hydro: alpine/non-alpine/tropical reservoir plants, runof-river plants, pumped storage plants

- Other renewables and waste: wind, photovoltaics, geothermal, biogas, wood, waste incineration

\subsection{Annual production volumes ${ }^{1}$}

The market shares of the individual electricity generation technologies in each geographic region with a corresponding electricity market are specified by the so-called "annual production volumes" of the activities supplying the market, i.e. the produced amount of the reference or by-product "electricity" in electricity generation activities in the case of electricity markets. Hence, the shares of contributing technologies are in proportion to this annual production of electricity in the supplying transforming activities (electricity generation technologies). Whether a certain technology contributes to the electricity market depends on the system model linking the unit processes (see Section 2.3).

\subsubsection{Main references used}

The figures for annual electricity production and imports in v3 are valid for the year 2008 (2009 for Switzerland and the US regions) and represent the net electricity fed into the grid at the high, medium or low voltage level. These figures represent the total production over the year and do not consider any daily or seasonal fluctuations. Data for 2008 were the most recent consistent statistics available when work for ecoinvent v3 was started. The main source of annual electricity production used to specify the ecoinvent electricity market compositions (representing the supply mixes) is the report "Life Cycle

\footnotetext{
"The term "annual production volume" has to be used for the amount of electricity produced per year according to the official ecoinvent terminology despite of the fact that electricity does not have a "physical" volume.
} 
Table 1 Country codes of all geographies with electricity markets in ecoinvent v3

\begin{tabular}{|c|c|c|c|}
\hline Country/Geography & Country Code & Country/Geography & Country Code \\
\hline Australia & $\mathrm{AU}$ & Malaysia & MY \\
\hline Austria & AT & Mexico & MX \\
\hline Belgium & $\mathrm{BE}$ & Netherland & NL \\
\hline Bosnia and Herzegovina & $\mathrm{BA}$ & Norway & NO \\
\hline Brazil & BR & Peru & $\mathrm{PE}$ \\
\hline Bulgaria & BG & Poland & $\mathrm{PL}$ \\
\hline Chile & $\mathrm{CL}$ & Portugal & PT \\
\hline China & $\mathrm{CN}$ & Romania & $\mathrm{RO}$ \\
\hline Croatia & HR & Russia & RU \\
\hline Czech Republic & $\mathrm{CZ}$ & Saudi Arabia & SA \\
\hline Denmark & DK & Serbia & $\mathrm{RS}$ \\
\hline Finland & FI & Slovakia & SK \\
\hline France & FR & Slovenia & SI \\
\hline Germany & $\mathrm{DE}$ & South Africa & ZA \\
\hline Greece & GR & South Korea & KR \\
\hline Hungary & $\mathrm{HU}$ & Spain & ES \\
\hline India & IN & Sweden & SE \\
\hline Indonesia & ID & Switzerland & $\mathrm{CH}$ \\
\hline Iran & IR & Taiwan & TW \\
\hline Ireland & IE & Tanzania & $\mathrm{TZ}$ \\
\hline Italy & IT & Thailand & $\mathrm{TH}$ \\
\hline Japan & JP & Turkey & TR \\
\hline Luxembourg & LU & Ukraine & UA \\
\hline Macedonia & MK & United Kingdom & GB \\
\hline \multicolumn{2}{|c|}{$\begin{array}{l}\text { United States - North American Energy Reliability } \\
\text { Corporation Regions (NERC) }\end{array}$} & \multicolumn{2}{|c|}{ Canada (13 Provinces/Territories) } \\
\hline Alaska Systems Coordinating Council & ASCC & Alberta & $\mathrm{CA}-\mathrm{AB}$ \\
\hline Florida Reliability Coordinating Council & FRCC & British Columbia & CA-BC \\
\hline Hawaiian Islands Coordinating Council & HICC & Manitoba & CA-MB \\
\hline Midwest Reliability Organization & MRO, US only ${ }^{1}$ & Québec & Québec \\
\hline Northeast Power Coordinating Council & NPCC, US only ${ }^{1}$ & New Brunswick & CA-NB \\
\hline Reliability First Corporation & RFC & Newfoundland and Labrador & CA-NF \\
\hline SERC Reliability Corporation & SERC & Northwest Territories & CA-NS \\
\hline Southwest Power Pool & SPP & Nova Scotia & CA-NT \\
\hline Texas Regional Entity & TRE & Nunavut & CA-NU \\
\hline Western Electricity Coordinating Council & WECC, US only $^{1}$ & Ontario & $\overline{\mathrm{CA}-\mathrm{ON}}$ \\
\hline \multirow{3}{*}{\multicolumn{2}{|c|}{$\begin{array}{l}1 \text { The NERC regions MRO, NPCC and WECC overlap to } \\
\text { certain extend with Canadian provinces. In order to avoid } \\
\text { double counting of electricity, these regions are defined in the } \\
\text { North direction according to the political borders between } \\
\text { Canada and the United States. }\end{array}$}} & Prince Edward Island & CA-PE \\
\hline & & Saskatchewan & CA-SK \\
\hline & & Yukon & CA-YK \\
\hline
\end{tabular}

New markets compared to v2.2 are marked in grey shading

Inventories of Electricity Mixes and Grid" (Itten et al. 2012). This document can be regarded as an update and extension of the ecoinvent v2 report No.6-XVI "Strommix und Stromnetz" (Frischknecht et al. 2007) and contains data regarding the 
annual electricity production of all generation technologies in all countries present in ecoinvent v3, data on electricity imports as well as country-specific electricity losses in the grid and emissions due to electricity transmission and transformation. It is based on statistics by the International Energy Agency IEA, but in some places provides a higher resolution in terms of generation technologies corresponding to the resolution of ecoinvent. The ecoinvent datasets in general use data from the IEA statistics directly. Where Itten et al. provide a higher resolution in terms of generation technologies, this source was used.

\subsubsection{Definitions}

Wherever possible, gross production values were implemented as a parameter in the datasets. The definition of gross and net electricity production is taken from IEA (2010) as follows: "Gross electricity production is measured at the terminals of all alternator sets in a station; it therefore includes the energy taken by station auxiliaries and losses in transformers that are considered integral parts of the station. Net electricity production is defined as gross production less own use of power plants and is measured at the station busbars". The gross production values in IEA (2010) refer to the sum of the two categories "main activity producers" and "autoproducers". Whereas main activity producers generate electricity and/or heat for sale to third parties (i.e. mainly, but not only to the public grid), autoproducers mostly generate power for their own use. This electricity is not delivered to the public grid and is not intended to be modelled as contributing to the $\mathrm{v} 3$ electricity markets. According to the statistics, the worldwide share of electricity from autoproducers amounts to $6 \%$. Due to the lack of detailed data in the statistics, it was (with few exceptions) not possible to subtract the amount of the autoproducers' electricity from the gross IEA/OECD value. Only autoproducers in the aluminium industry (global datasets), in coal mining in China and from the Swiss Federal Railways in Switzerland are modelled separately in ecoinvent v3 with specific electricity generation and market activities. These separately modelled autoproducers do not contribute to the "normal" electricity markets, but their production is subtracted from the total production given in the IEA statistics. Another difficulty arises from the fact that the IEA/ OECD electricity statistics only consider electricity produced in pure electricity plants as well as in heat and power plants. Electricity as by-product from specific industrial processes delivered to the public grid is not accounted for, resulting in a minor mismatch between IEA/OECD electricity statistics and the v3 market shares of electricity as reference or by-product from different transforming activities.
2.2 Electricity production mixes and electricity markets (electricity supply mixes)

The Data Quality Guidelines (Weidema et al. 2013) define the different mixes present in ecoinvent $\mathrm{v} 3$ as follows: "A production mix represents the production-volume-weighted average of the suppliers of a specific product within a specific geographic region. A supply mix is a production mix with the addition of the import of the specified product to the specified geographic region. A consumption mix is the output of a market activity. Consumption mixes represent productionvolume-weighted averages of the suppliers to a specific market". The electricity production mixes and markets in ecoinvent are modelled with the reference product " $1 \mathrm{kWh}$ of electricity".

\subsubsection{Electricity production mixes}

An electricity production mix (PM) is defined as the mix of electricity produced in a certain geographic region without taking into account any trade with neighbouring areas. In general, PMs do not represent a real marketable product and are no longer supported and recommended for use by ecoinvent v3. PMs for electricity at high voltage have been maintained for the sake of continuation, i.e. maintaining the version 2 database content. However, the v2 and the v3 PM cannot be directly compared due to the fact that the v2 electricity PM datasets include transmission infrastructure and associated emissions, while the $\mathrm{v} 3 \mathrm{PM}$ datasets show the pure composition of this mix with the corresponding generation technologies but without the transmission infrastructure and associated emissions. Further, the PM in v2 included all production technologies in a certain country, whereas version 3 provides PMs at high voltage with inputs of electricity at high voltage only.

\subsubsection{Electricity markets (supply mixes)}

Electricity markets correspond to the former electricity supply mixes in ecoinvent $\mathrm{v} 2$. Besides inputs of their reference product, market datasets additionally account for transport, losses, wholesaler and/or retailer activities as well as waste occurring from these activities (Weidema et al. 2013). Accordingly, electricity market datasets in ecoinvent $\mathrm{v} 3$ consist of electricity inputs from domestic production and imports from neighbouring countries, transmission and transformation infrastructure, associated emissions, and a direct link to electricity from the market itself accounting for the losses during transmission (see Fig. 1). All the necessary data are taken from Itten et al. (2012).

Geographical definition of the markets In general, the ecoinvent electricity markets correspond to the individual 
Fig. 1 Structure of and links between electricity markets (high, medium, and low voltage level) in ecoinvent v3. Emissions of $\mathrm{N}_{2} \mathrm{O}$, $\mathrm{O}_{3}$ and $\mathrm{SF}_{6}$ are direct emissions of the market activities. Some of the electricity producing activities as well as imports are classified as constrained in the consequential version of the database and therefore do not supply the markets

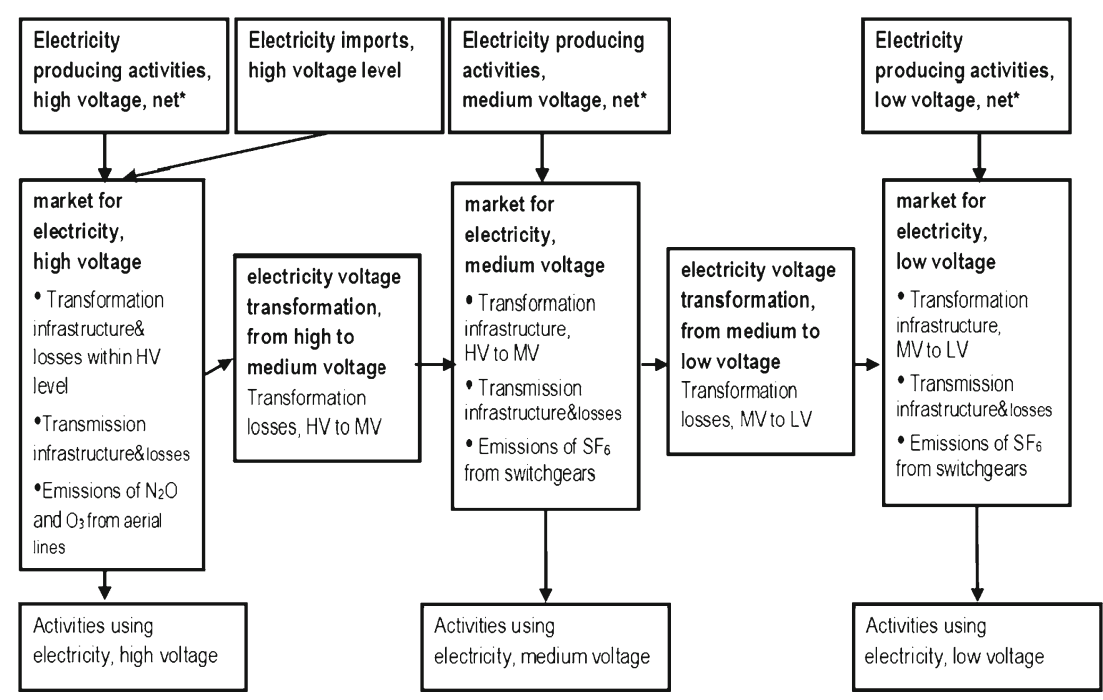

countries (except for the USA and Canada), since country borders most often represent markets with specific regulations for production and trade of electricity, which justifies the existence of "non-global market activities" according to Weidema et al. (2013). Often, exports and imports of electricity between neighbouring markets are restricted due to either physical limitations (transmission lines), or administrative reasons. The markets are modelled with Geographical Information System (GIS) data in the Keyhole Markup Language (KML) (see chapter on geographical localisation in Weidema et al. (2013)). Overlapping geographies are not allowed in ecoinvent v3, i.e. it is no longer possible to have, for example, an electricity market for the whole of Europe and additionally for single European countries as in v2. ${ }^{2}$ In large countries, the energy carriers used for electricity production can vary significantly between different regions with the consequence of potentially large differences in terms of associated environmental burdens. LCA case studies with processes more precisely located than on a country level will profit from a subdivision of large electricity markets, which can better reflect the actual electricity mix used. Partitioning can take place according to existing electricity grid networks or according to sub-region (state, provincial) borders. Both options are present in ecoinvent v3: Whereas the United States are split according to electricity grid networks in line with the North American Energy Reliability Corporation Regions (NERC), Canada is split into provinces/territories (see Table 1). Partitioning of the electricity market in other large countries with large geographical differences in electricity production-mainly China, Australia, Russia and India-will be considered for a future version of ecoinvent.

\footnotetext{
${ }^{2}$ Because of a special linking mode for the production mixes in the database, this rule does not apply to them and overlapping is possible according to Weidema et al. (2013).
}

Model for the electricity markets Electricity exports are not explicitely taken into account in the supply mixes, i.e. the composition of exports from a specific market as imports to another is assumed to correspond to the supply mix of the exporting market. This type of modelling corresponds to the model "M2" according to Ménard et al. (1998). Different approaches to modelling the complex situation of electricity markets and trading and their use in general LCA and the ecoinvent database are discussed in Itten et al. (2012).

Electricity voltage levels The electricity markets exist on three electricity voltage levels defined according to Itten et al. (2012):

- High voltage level - above $24 \mathrm{kV}$ (large scale industry)

- Medium voltage level — between 1 and $24 \mathrm{kV}$ (medium to small scale industry, service sector and public buildings)

- Low voltage level-below $1 \mathrm{kV}$ (households)

In ecoinvent $\mathrm{v} 3$, most electricity producing activities are assumed to generate electricity at high voltage level as reference or by-product (see Treyer and Bauer 2013). Electricity from photovoltaics is modelled as low voltage generation. This modelling assumption quite closely represents reality; however, small wind turbines or large open ground photovoltaic plants may generate electricity at medium voltage level. Detailed information on this was not available. Since the influence of this modelling assumption is not of high importance for the impact assessment results, it can be regarded as justifiable. Medium and low voltage markets are therefore mostly fed by the transformation datasets from the voltage level above.

Electricity transformation and transmission losses and emissions Losses during transformation and transmission of electricity as well as losses from gross to net electricity 
production at the power plants are modelled in ecoinvent $\mathrm{v} 3$ based on Itten et al. (2012). Electricity consumption by pumped storage hydropower plants is accounted for directly in the electricity producing pumped storage hydropower datasets and is not part of the general losses in the grid. The electricity inputs to market datasets (with the functional unit of $1 \mathrm{kWh}$ ) sum up to slightly more than $1 \mathrm{kWh}$, thus accounting for the transmission losses on each voltage level. Transformation losses between the three voltage levels are modelled in separate transformation datasets. Transformation losses within the high voltage level are included directly in the datasets for the high voltage market. The transformer station itself is included in the transmission infrastructure dataset and is therefore an input to the market datasets. The market datasets for high voltage electricity contain emissions of dinitrogen monoxide $\left(\mathrm{N}_{2} \mathrm{O}\right)$ and ozone $\left(\mathrm{O}_{3}\right)$ built in the electro-magnetic field near high voltage aerial lines. The market datasets for medium and low voltage contain sulphur hexafluoride $\left(\mathrm{SF}_{6}\right)$ emissions from the switchgears (Itten et al. 2012). Most of $\mathrm{SF}_{6}$ emissions (ca. $95 \%$ ) are caused by the high voltage level switchgear, which are allocated to the electricity demand on medium voltage.

Electricity imports Electricity imports are modelled at high voltage level and are quantified according to Itten et al. (2012). The complete transmission infrastructure including cross-border lines is taken into account in the market datasets. The electricity is considered to be imported when it has crossed the boundaries of a specific geography and is therefore not available on the electricity market of the delivering country. The composition of the imported electricity corresponds to the market mix of the original geographic region, i.e. the domestic production in that geographic region plus the imports into it. In the case of imports from countries without specific electricity markets in ecoinvent $\mathrm{v} 3$ (AR, PY, VE, UY, $\mathrm{EE}, \mathrm{BT}, \mathrm{AZ}, \mathrm{GE}, \mathrm{TM}^{3}$ ), the dominating generation technologies in each of the countries was determined with IEA statistics IEA (2012). Then, direct activity links to these technologies in neighbouring countries were set, or, when this was not possible, the global dataset of the specific technology was linked to.

Special electricity markets The following special electricity markets with corresponding naming of the electricity generated as reference or by-product in the producing activities have been implemented in ecoinvent v3 (see Treyer and Bauer (2013) for details):

- "market for electricity, high/medium/low voltage, labelcertified, GLO/CH": These markets collect the special

\footnotetext{
${ }^{3}$ Argentina, Paraguay, Venezuela, Uruguay, Estonia, Bhutan, Azerbaidjan, Georgia, Turkmenistan
}

electricity type "label-certified" modelled for Switzerland.

- "market for electricity, high voltage, for Swiss Federal Railways, GLO/CH"

- "market for electricity, high voltage, for internal use in coal mining, GLO/CN"

- "market for electricity, high/medium voltage, aluminium industry, GLO"

With exception of the label-certified market, these special electricity types are examples of autoproducers, i.e. the electricity produced is not supplied to the public grid but used internally. As a consequence, transport activities of the Swiss Federal Railways, coal mine operation activities in China, and aluminium production activities use electricity from these special markets for supply of their demand. Label-certified electricity represents "green" electricity from renewables, which can be purchased as a special product with a mark-up. It can be used as input in activities of consumers, who purchase this certified electricity.

2.3 Electricity markets in the attributional and consequential versions of the database

Currently, there are two versions of the linked ecoinvent v3 database: an "attributional" and a "consequential" one (Weidema et al. 2013). The "allocation, default" system model represents the attributional approach. This model applies partitioning, i.e. allocation. The "substitution, consequential, long-term" system model instead applies substitution, i.e. system expansion, based on a long-term perspective. The different algorithms linking the unit processes determine the (electricity) market compositions, i.e. determine which generation activities supply the market of specific product.

\subsubsection{Attributional modelling of electricity markets}

In the attributional "allocation, default" system model, each market activity is supplied by all transforming activities within the geographical area of the market activity, which produce the market reference product as an output (Weidema et al. 2013).

The attributional electricity markets (high/medium/low voltage) are linked to average current suppliers and are therefore supplied by all transforming activities with electricity (high/medium/low voltage) as reference product or byproduct in the geographical area of the market as well as by imports from neighbouring markets or specific generation technologies. The market shares of these supplying activities are proportional to the available annual electricity production volume in these activities. 


\subsubsection{Consequential modelling of electricity markets}

In the "substitution, consequential, long-term" version, constraints in terms of electricity generation capacity are taken into account. Only unconstrained suppliers, which will respond to changes in demand over the long term, contribute to the markets (Weidema et al. 2013).

The "long-term" perspective of the consequential system model implies that these electricity markets are not supposed to represent the marginal $\mathrm{kWh}$ covering additional power demand on the hourly, daily or seasonal basis with already installed generation capacities, but the additional capacity to be installed in the future for covering increasing (or stable) electricity demand reflecting a long-term trend of growing (or stable) electricity market composition. There are two types of constraints for electricity generation in ecoinvent: the first is introduced with the categorization of electricity as by-product. The second depends on the "technology level" of the activities generating electricity as a reference product, which is defined in the datasets.

Electricity produced as a by-product in heat and power cogeneration plants or from treatment activities is assumed to be constrained, as the main purpose of the corresponding activities is not the production of electricity and therefore their electricity output is assumed not to respond to an increase in demand.

The technology level of generation activities does not necessarily reflect the age of technologies, but rather their long-term economic competitiveness on the markets (Weidema et al. 2013). It can additionally be used for considering non-economic constraints, such as environmental or political constraints. "Current" is the default level. "Outdated" is used for technologies no longer in use; "Old" refers to technologies currently taken out of use. "Modern" refers to technologies currently used when installing new capacity. "New" technologies are assumed to be technically superior to modern technologies, but are not yet the most commonly installed.

In ecoinvent $\mathrm{v} 3$, all electricity markets are assumed to be increasing or stable, so that new generation capacity has to be installed. The high voltage electricity markets in the current consequential database version are supplied by activities with electricity as reference product and being classified as "Modern". "Current" activities only supply the markets if "Modern" activities do not exist. "New" activities would supply the markets if no "Modern" or "Current" classified activities would exist. Such activities do not yet exist in ecoinvent. The technology level categorization of generation technologies is based on the authors' judgment whether certain fuels and technologies will be expanded (or at least, further used) in each electricity market. This has generally been done considering the current global trend in the power generation sector with few country-specific exceptions.

Table 2 summarises the two approaches by showing which technologies supply the attributional and the consequential electricity markets, respectively, in ecoinvent v3.01. Justifications for each decision are given - it should be noted that region-specific revision is envisaged for v3.1. The market shares of unconstrained suppliers are proportional to their current available annual production volume.

The activities for transformation of electricity (which are the main suppliers of the medium and low voltage markets) are classified as "Current" technology. As a consequence, electricity generation with photovoltaic systems (generating low voltage electricity) also has to be classified as "Current"; classification as "Modern" would lead to low voltage markets only supplied by photovoltaics (as the only unconstrained supplier). In order to achieve a consistent classification of generation technologies supplying the consequential markets, classification of voltage transformation activities as well as photovoltaic electricity generation will be changed to "Modern" for the next release of the database. Also the classification of electricity imports will be changed from "Current" to "Modern" in order to allow the inclusion of electricity imports as suppliers on consequential electricity markets.

\section{Life cycle inventory data}

\subsection{Transformation and transmission losses}

All data on transmission and transformation losses are based on Itten et al. (2012), Tab. 4.26, and are shown in Table $i$ in the electronic supplementary material (ESM) for all electricity markets and Table 3 for selected exemplary markets. The total geography-specific share of electricity losses (i.e. electricity lost between feed-in at the power plants and end-use divided by the amount of electricity fed in) were calculated by Itten et al. (2012) based on statistics on total electricity supply and losses in each geographic region (IEA 2010, 2011). The figures for voltage level specific distribution losses on the three different voltage levels during transformation and transmission in each geography are based on data from Switzerland as no other country-specific data were available. Using these Swiss values for losses on the three voltage levels and the total losses given in Itten et al. (2012), the losses on the different levels were calculated for all geographical regions. All these data have been implemented as parameters and in mathematical relations in the datasets, so that they can easily be adapted if geography-specific loss data would be available. The values in bold indicate that, in general, $39 \%$ of all losses occur on the high voltage level; only $13 \%$ on medium voltage level, and 
Table 2 Technologies supplying the attributional or the consequential electricity markets according to the different modelling approaches

\begin{tabular}{|c|c|c|c|}
\hline & Attributional & Consequential & Justification for constraints \\
\hline Coal & Hard coal, lignite, peat & Hard coal, lignite & $\begin{array}{l}\text { Electricity generation from peat is assumed to be } \\
\text { constrained due to environmental and economic } \\
\text { concerns }\end{array}$ \\
\hline Gas & $\begin{array}{l}\text { Natural gas (in conventional and } \\
\text { combined cycle power plants with } \\
\text { and without combined heat and } \\
\text { power); Industrial gases (blast } \\
\text { furnace gas, coal gas) }\end{array}$ & $\begin{array}{l}\text { Natural gas, in combined cycle } \\
\text { power plants without combined } \\
\text { heat and power }\end{array}$ & $\begin{array}{l}\text { Electricity generation with CHP plants is constrained } \\
\text { as a by-product. It is assumed that combined cycle } \\
\text { plants will be built instead of conventional plants. } \\
\text { Industrial gases are by-products of industrial processes, } \\
\text { i.e. constrained as fuels for power generation. }\end{array}$ \\
\hline Oil & Oil & $\begin{array}{l}\text { Only in the following countries: } \\
\text { CA-NU, CN, BR, IR, RU, SA }\end{array}$ & $\begin{array}{l}\text { Assumption based on availability of domestic oil } \\
\text { resources, environmental and political boundary } \\
\text { conditions. }\end{array}$ \\
\hline Nuclear & $\begin{array}{l}\text { Pressure water reactors, boiling water } \\
\text { reactors }\end{array}$ & $\begin{array}{l}\text { Pressure water reactors, boiling } \\
\text { water reactors (exceptions: No } \\
\text { nuclear power in Switzerland, } \\
\text { Germany, and Japan) }\end{array}$ & Current $^{\mathrm{a}}$ nuclear policy. \\
\hline Hydro & $\begin{array}{l}\text { Reservoir plants, alpine/non-alpine/ } \\
\text { tropical; run-of-river plants; pumped } \\
\text { storage plants }\end{array}$ & $\begin{array}{l}\text { Reservoir plants, alpine/ } \\
\text { non-alpine/tropical; run-of- } \\
\text { river plants; pumped storage } \\
\text { plants }\end{array}$ & \\
\hline $\begin{array}{l}\text { Other } \\
\text { renewables } \\
\text { and waste }\end{array}$ & $\begin{array}{l}\text { Wind, geothermal, biogas, wood, waste, } \\
\text { photovoltaics (on low voltage level) }\end{array}$ & $\begin{array}{l}\text { Wind, geothermal, photovoltaics } \\
\text { (on low voltage level) }\end{array}$ & $\begin{array}{l}\text { Electricity from biogas, wood and waste is } \\
\text { constrained as a by-product. }\end{array}$ \\
\hline Imports & Imports from neighbouring countries & No imports & $\begin{array}{l}\text { Conservative assumption, since it's unclear whether } \\
\text { increasing demand can be supplied by imports. }\end{array}$ \\
\hline
\end{tabular}

\footnotetext{
${ }^{\text {a }}$ The classification of the technology level was made under the influence of the accident in Fukushima, with Switzerland and Germany deciding to step out of nuclear power and Japan assumed to phase out. This might have changed in the meanwhile for Japan
}

$48 \%$ during distribution in the low voltage grid. The highest total losses of electricity occur in Bosnia and Herzegovina $(22.8 \%)$. In contrast, only $1.5 \%$ of the produced electricity is lost in Luxembourg. According to Itten et al. (2012), the high differences between the countries result from differences in population densities, transport distances and the state of infrastructure.

\subsection{Annual production volumes of electricity production}

The annual production volumes of electricity in the electricity production and import datasets determining their shares on the electricity markets are valid for the year 2008 (2009 for Switzerland and the US regions). These figures are entries in the electricity generation unit processes in the database (see Treyer and

Table 3 Electricity losses in the three markets with the highest and lowest losses, respectively

\begin{tabular}{|c|c|c|c|c|c|c|c|c|}
\hline \multirow{2}{*}{$\begin{array}{l}\text { Country } \\
\text { code }\end{array}$} & \multirow{2}{*}{$\begin{array}{l}\text { Total electricity } \\
\text { supply [GWh] }\end{array}$} & \multirow{2}{*}{$\begin{array}{l}\text { Total losses } \\
{[\mathrm{GWh}]}\end{array}$} & \multirow{2}{*}{$\begin{array}{l}\text { Total losses, share } \\
\text { on total supply }\end{array}$} & \multirow{2}{*}{$\begin{array}{l}\text { Losses high voltage } \\
\begin{array}{c}\text { Transformation and } \\
\text { transmission }\end{array}\end{array}$} & \multicolumn{2}{|c|}{ Losses medium voltage } & \multicolumn{2}{|c|}{ Losses low voltage } \\
\hline & & & & & Transformation & Transmission & Transformation & Transmission \\
\hline \multicolumn{2}{|c|}{$\begin{array}{l}\text { Distribution of losses on the } \\
\text { different voltage levels [-] }\end{array}$} & & & 0.06 and 0.33 & 0.08 & 0.05 & 0.24 & 0.24 \\
\hline $\mathrm{BA}$ & 10,100 & 2,300 & 0.228 & 0.0888 & 0.0182 & 0.0114 & 0.0547 & 0.0547 \\
\hline $\mathrm{TZ}$ & 4,400 & 900 & 0.205 & 0.0798 & 0.0164 & 0.0102 & 0.0491 & 0.0491 \\
\hline IR & 204,000 & 38,000 & 0.186 & 0.0726 & 0.0149 & 0.0093 & 0.0447 & 0.0447 \\
\hline SK & 26,900 & 1,000 & 0.037 & 0.0145 & 0.0030 & 0.0019 & 0.0089 & 0.0089 \\
\hline MY & 103,300 & 2,500 & 0.024 & 0.0094 & 0.0019 & 0.0012 & 0.0058 & 0.0058 \\
\hline LU & 6,700 & 100 & 0.015 & 0.0058 & 0.0012 & 0.0007 & 0.0036 & 0.0036 \\
\hline
\end{tabular}

All values for the other geographies are listed in Table $\mathrm{i}$ in the electronic supplementary material. Calculation with data from Itten et al. (2012). "Total losses, share on total supply" refers to net electricity generated at the power plants and fed into the grid; these shares are country specific. The distribution of total losses during transformation and transmission at the different voltage levels (in bold) are identical for all countries and based on figures from Switzerland. Other country-specific figures for this distribution of total losses were not available 
Bauer 2013). All geography and technology-specific annual production volumes and specific shares of technologies for each of the 71 geographic regions are listed in Tables ii and iii (attributional) and Tables iv and v (consequential) in the ESM. The figures are discussed in Section 4.

\subsection{Electricity imports}

Figure 2 gives an overview of the shares of imported electricity into the electricity markets of the geographical regions in ecoinvent $\mathrm{v} 3$, calculated as:

amount_of_imported_electricity

amount_of_domestic_electricity_production + amount_of_imported_electricity

Absolute numbers of electricity imports are shown in Tables vi to $\mathrm{x}$ in the ESM. Electricity trade within the USA, i.e. between the NERC regions, could not yet be modelled, but will be implemented in the next version of the database. Out of the top 30 importing countries, 21 are located in Europe, and 6 are Canadian provinces/territories. The maximum amount of imported electricity on the electricity market is found in Prince Edward Island in Canada (95\% of total electricity on the market, but only $1 \mathrm{TWh}$ in absolute terms) and in Luxembourg (70 \%, 6.8 TWh). The biggest importers in absolute terms are Italy (43.4 TWh or $13 \%$ ), Brazil (42.9 TWh or $8.6 \%$ ) and Germany (41.7 TWh or $6.6 \%$ ).

\subsection{Special electricity markets}

Annual production volumes for the label-certified electricity in Switzerland are listed in Table xi in the ESM.

\section{Results and discussion}

All the results can essentially be derived from Tables ii to $\mathrm{v}$ in the ESM, which show the net annual production of grid- connected electricity generation activities and the amounts of imported electricity for all 71 geographic regions with electricity markets according to the attributional and the consequential system models of ecoinvent $\mathrm{v} 3$. Table 1 provides all abbreviations for country codes.

\subsection{Domestic electricity generation (production mixes) —attributional}

The domestic electricity generation is defined as the "electricity production mix" in a certain geographic region. The worldwide electricity production is dominated by electricity from hard coal (41\%). Electricity from natural gas (21\%), hydropower $(16 \%)$ and nuclear plants $(15 \%)$ also have large shares. The rest is produced from oil $(4 \%)$ and various non-hydro renewables $(3 \%)$. Technology shares vary a lot between the different geographic regions. Even if renewables profited from impressive growth rates in some countries in the last years, fossil fuels (coal, oil, natural gas and industrial gases) still strongly dominate electricity production in most countries. Only in 11 out of the 71 geographic regions, the share of fossil fuels is below $25 \%$. Electricity is generated with fossil fuels only in the two regions Nunavut (CA-NU) and Saudi Arabia (SA). Nuclear power plants contribute more than $50 \%$ to the production mixes in three countries (FR, SK, BE). Hydropower is the most frequently used renewable technology. It plays a significant role in the production mixes of six Canadian provinces/territories(CA-MB, Québec, CA-NF, CA-BC, CAYK and CA-NT), as well as in Norway and Brazil with more than $65 \%$ of the production mix. Other renewables usually do not hold large shares. One exception is the tiny Canadian province "Prince Edward Island", which produces $68 \%$ of the electricity with wind power-but at the same time is the largest importer of the 71 geographic regions with $95 \%$ of consumed electricity supplied by imports. In absolute terms, Germany produces the largest amount of electricity with wind as well as with photovoltaics (40 TWh and 4.2 TWh in 2008,
Fig. 2 Share of imports on the electricity markets on high voltage level in ecoinvent $\mathrm{v} 3$. The following countries do not import electricity: $A U, C A-N T, C A-N U$, $C A-Y K, I D, I E, I R, J P, K R, M Y, P E$, $S A, T H, T W$ and $T Z$. No imports were modelled between the regions of the USA, only with the neighbouring geographies in Canada and Mexico. For geography acronyms (country codes), see Table 1

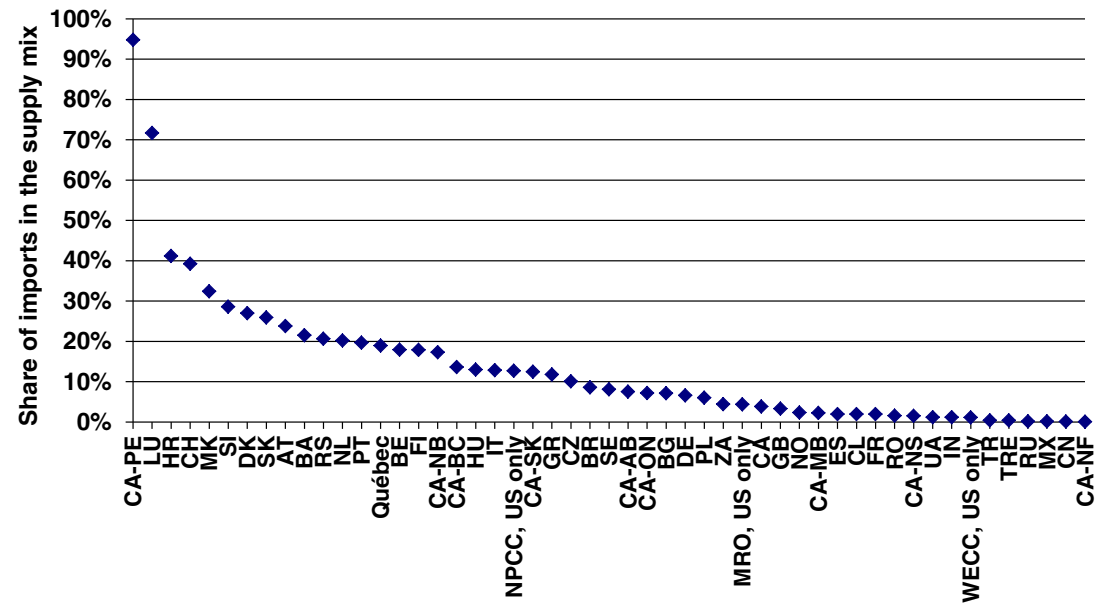


respectively, which corresponds to $6.9 \%$ and $0.7 \%$ of electricity produced in Germany). In relative terms, the largest share of photovoltaics in total electricity production is to be found in Spain with $0.8 \%$ (2.4 TWh). However, the electricity production mixes provided by ecoinvent represent the high voltage level and do therefore not include electricity from photovoltaics, which is modelled as low voltage level generation. Considering the very small shares of this technology on the total electricity production in all geographic regions, this neglection will have only minor influences on cumulative LCI and LCIA results of the production mixes.

\subsection{Electricity markets: domestic electricity production} and imports (supply mixes) - attributional

The attributional electricity markets (supply mixes) include electricity imports in addition to the domestic electricity production. The shares of different electricity producing technologies and imports vary significantly between the geographic regions. Figure 3 shows the electricity market composition of the seven largest electricity markets worldwide and of the extremes of the 71 electricity markets in terms of use of renewables, nuclear and fossil fuels. $42 \%$ of global electricity was produced in the seven largest markets in 2008. They mostly rely on fossil fuels, adding nuclear power and some hydropower with (nearly) no imports. The two groups with largest share of renewables and fossil fuels, respectively, show a large contrast between three Canadian provinces: Whereas CA-MB and Québec rely largely on hydropower, the tiny territory Nunavut relies to $100 \%$ on oil power. The example of Canada highlights the importance of splitting large countries into smaller regions (Fig. 4). The electricity markets in Canada vary largely in view of imports and production technologies, from zero imports (CA-NT, CA-NU, CA-YK) to $95 \%$ imports (CA-PE) and from nearly $100 \%$ renewables (CA-MB, CA-NF, CA-YK, CA-BC, CA-NT, Québec) to $100 \%$ fossil fuels (CA-NU).

The attributional electricity markets include electricity imports in addition to the domestic electricity production. The imported electricity is again a supply mix consisting of domestic production and imports from neighbouring countries. As demonstrated in Fig. 2, some (small) countries heavily depend on electricity imports, which can substantially change the shares of electricity sources on the supply mix. The actual production origin of the electricity on the market (in terms of fuels and generation technologies) can therefore differ greatly from the domestic production mix, as shown in Fig. 5 for all geographic regions importing more than $20 \%$ of their electricity on the market. Three bars per geographic region show the changes from the production mix (left bar) to the supply mix with unspecified imports shown separately (middle bar) and the actual supply mix (right bar). The production mix corresponds to the electricity production mixes in ecoinvent v3 at high voltage (i.e. without electricity from photovoltaics at low voltage). The second bar corresponds to the electricity markets at low voltage (i.e. with electricity from suppliers at low voltage) with unspecific imports, and the third bar corresponds to the low voltage electricity markets with imports specified according to the fuel used for generation in the origin region.

Depending on the import shares, the highest changes between domestic production and the actual market supply occur in the small Canadian province of Prince Edward Island (CA-PE), where coal power contributes $41 \%$ to the market although there are no domestic coal power plants on the island. On the other hand, $74 \%$ of domestic electricity is generated from renewables (no hydro), whereas the supply

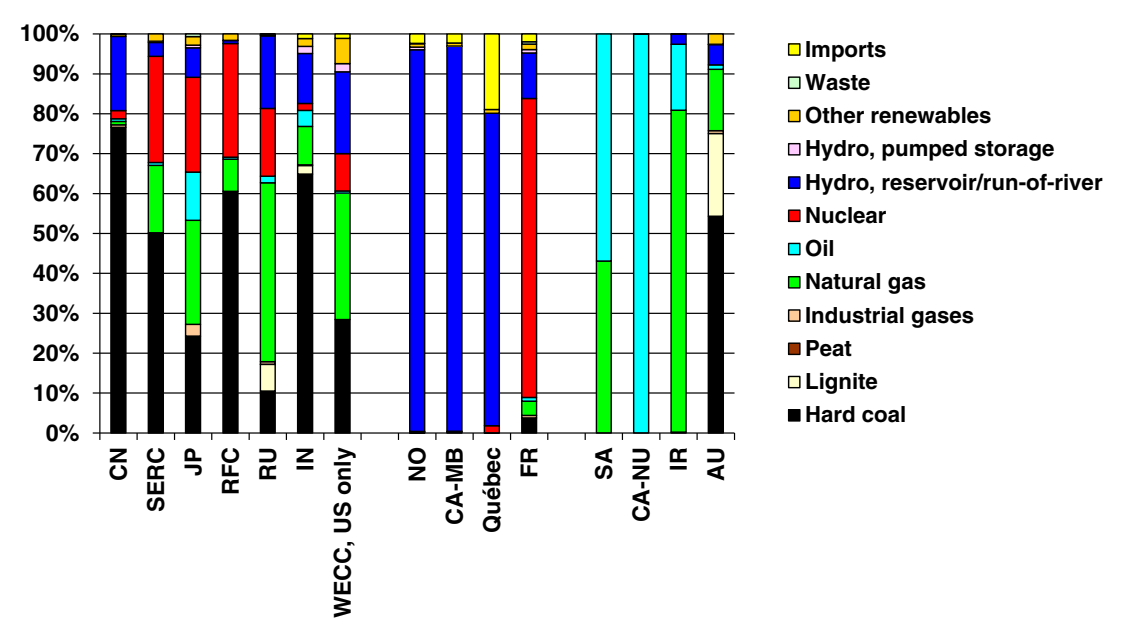

Fig. 3 Attributional ecoinvent v3 electricity markets in selected geographies. The group on the left (CN to WECC, USA only) represents the seven biggest electricity markets worldwide. The group in the middle represents the geographies with highest shares of non-fossil fuels (i.e. renewables (NO to Québec) and nuclear (FR), respectively). The group on the right represents the geographies with highest shares of fossil fuels
(SA to AU). "Other renewables" includes electricity from wood, biogas, wind and geothermal power. "Nuclear" includes pressure water reactors and boiling water reactors. "Natural gas" includes electricity production in conventional and combined cycle power plants with and without combined heat and power. "Industrial gases" include electricity from blast furnace gas and coal (coke) gas 
Fig. 4 Electricity markets of the 13 Canadian provinces/territories in 2008. For explanation of the categories, see Fig. 3

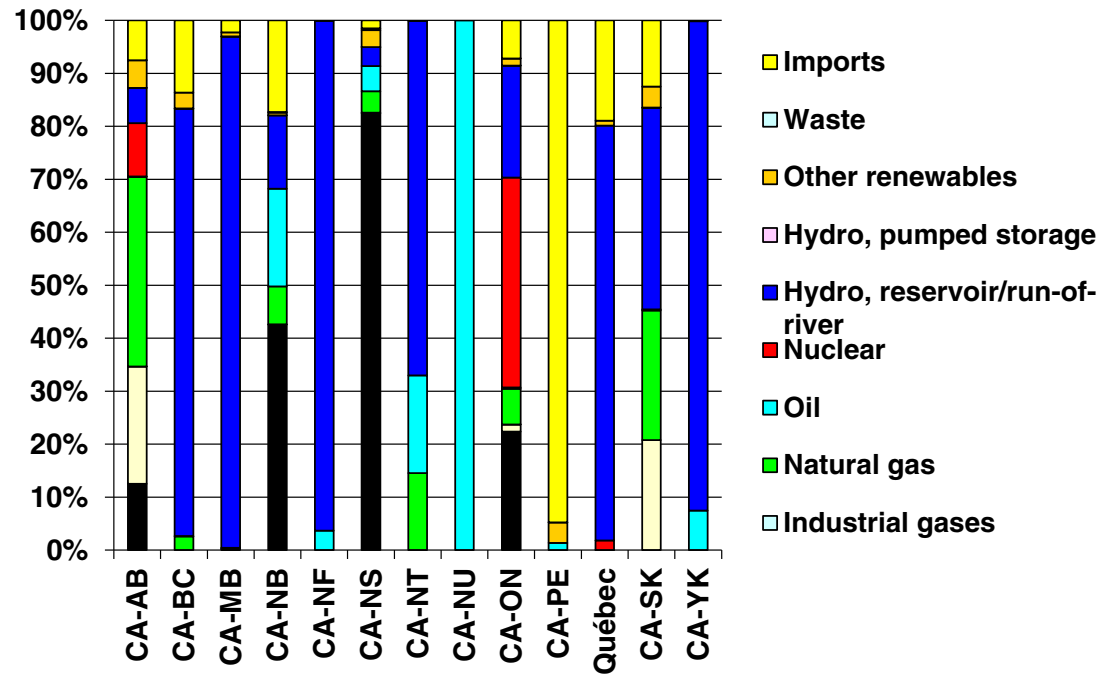

mix consists of $25 \%$ hydropower and only $5 \%$ other renewables. This means that from production to supply mix, CA-PE switches from a mainly renewables-based electricity mix to a half fossil fuel-based mix with a total change of $76 \%$ in electricity sources, i.e. if the production mix was $100 \%$ from oil and wind, these two technologies account for only $24 \%$ of the supply mix. The changes between production and supply mix however do not always correlate with the imported amounts. For example, Macedonia (MK) imports $32 \%$ of its electricity and only shows changes of $7.3 \%$; whereas Denmark with $27 \%$ of imports shows changes of $23 \%$ and shifts from a fossil-fuel based production mix (70 \% fossil fuels in the production mix vs. $53 \%$ fossil fuels in the supply mix) to more renewables $(30 \%$ in the production mix vs. $40 \%$ in the supply mix). The share of hydropower increases from nearly zero to $17 \%$ due to imports from Norway.

The change in the electricity mix as a consequence of imports therefore also depends heavily on differences in fuel use between domestic electricity generation and that in neighbouring countries.

\subsection{Attributional vs. consequential electricity markets}

The electricity markets calculated according to the unit process linking rules of the attributional and the consequential system models show different shares of technologies due to

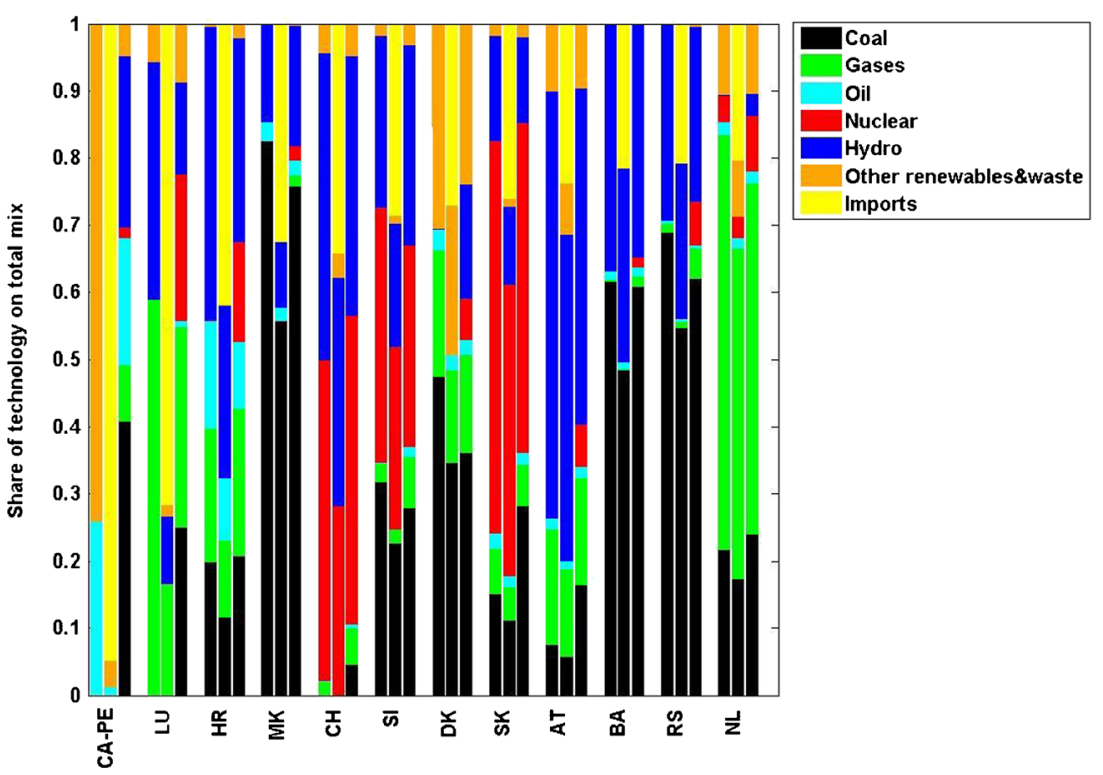

Fig. 5 Comparison of the shares of electricity origin in the domestic production mix at high voltage (left bar), the supply mix at low voltage with unspecified imports (middle bar) and the supply mix at low voltage with electricity imports specified according to the fuel used for power generation (right bar) in the geographical regions with more than $20 \%$ of imports. The different categories include: coal (hard coal, lignite, peat); gases (natural gas, blast furnace gas, coal gas); oil; nuclear (pressure/ boiling water reactors); hydro (reservoir plants alpine/non-alpine/tropical, run-of-river plants, pumped storage plants); other renewables and waste (wind, geothermal, biogas, wood, waste, photovoltaics) 
the fact that only unconstrained generation activities supply markets in the consequential system (see Table 2). Figure 6 shows the electricity markets at low voltage level, resulting from linking of the unit processes according to the attributional system model (left bar) and the consequential system model (right bar) for the 20 geographic regions showing the most significant differences between the two system models in terms of fuel types used for power generation.

As five generation technologies using fossil fuels are classified as constrained suppliers and do not contribute to the consequential mix (peat, natural gas in conventional power plants with and without CHP, natural gas in combined cycle power plants with CHP, oil in most geographic regions), renewables and nuclear (except $\mathrm{CH}, \mathrm{DE}, \mathrm{JP}$ ) in general have higher shares on the consequential markets than on the attributional ones.

As Fig. 6 shows the current modeling of consequential mixes with linking to unconstrained supplying transforming activities partially leads to somehow unrealistic consequential electricity markets in some geographical regions for various reasons. First, (new) technologies, which are currently not operating in a geographical region and therefore not supplying the electricity market, but are envisaged to do so in the near future, are not considered as the database does not contain inventory data for these technologies or the technology is not modelled for that specific region. Second, the market shares of the unconstrained technologies on the consequential markets are proportional to their current annual production, which means that technology-specific potentials for increasing the production and limitations of these potentials (due to political, economic and social constraints), respectively, are not taken into account. Additionally, electricity from combined heat and power generation (CHP) with heat as reference product does not supply the electricity markets in the consequential version. However, the rates of heat and electricity generation of CHP plants can be altered to some extent in reality in order to respond to changes in heat and electricity demand (i.e. electricity as by-product is not completely constrained), which is not taken into account in the inventories. Moreover, the technology levels have only been assumed roughly per technology instead of on a country-specific level (with few exceptions). The Swiss (CH in Fig. 6) electricity market in the consequential version of the database can be considered as a good example illustrating most of these shortcomings: According to the current governmental energy strategy, natural gas and geothermal power plants are likely to be installed within the next one to two decades replacing nuclear capacities to be phased out. However, neither natural gas, nor geothermal plants are currently installed and therefore, these are not supplying the consequential market. In fact, only electricity from hydro, wind, and solar power (the latter two being part of the category "other renewables and waste" dominated by waste incineration) is not constrained as by-product or via technology classification. These technologies contribute to the Swiss consequential market; however, in proportion to their current production which neither reflects the different potentials for capacity expansion, nor natural, political, and social boundary conditions, which tend to limit expansion of both hydro and wind power to a much higher extent than photovoltaics. With sufficient political support, also electricity from small natural gas fuelled cogeneration units might be used for partial replacement of nuclear. However, electricity from such CHP plants is generated as by-product of the reference product heat and is therefore constrained. Disregarding such implicit technology constraints and potential political incentives leads to a consequential electricity market supplied almost exclusively by hydro power which is very unlikely to represent future capacity expansion or replacement of currently operating capacities in Switzerland. For other countries, the composition of the electricity markets according to the consequential system model can be considered as realistic, e.g. the consequential market in Germany
Fig. 6 Comparison of selected attributional (left bars) and consequential (right bars) electricity markets at low voltage for the 20 geographical regions showing the highest changes between the two modelling approaches in terms of fuel types used for power generation. Table 2 shows which technologies supply the markets according to the two different system models used for linking the unit processes. For explanation of the categories see Fig. 5

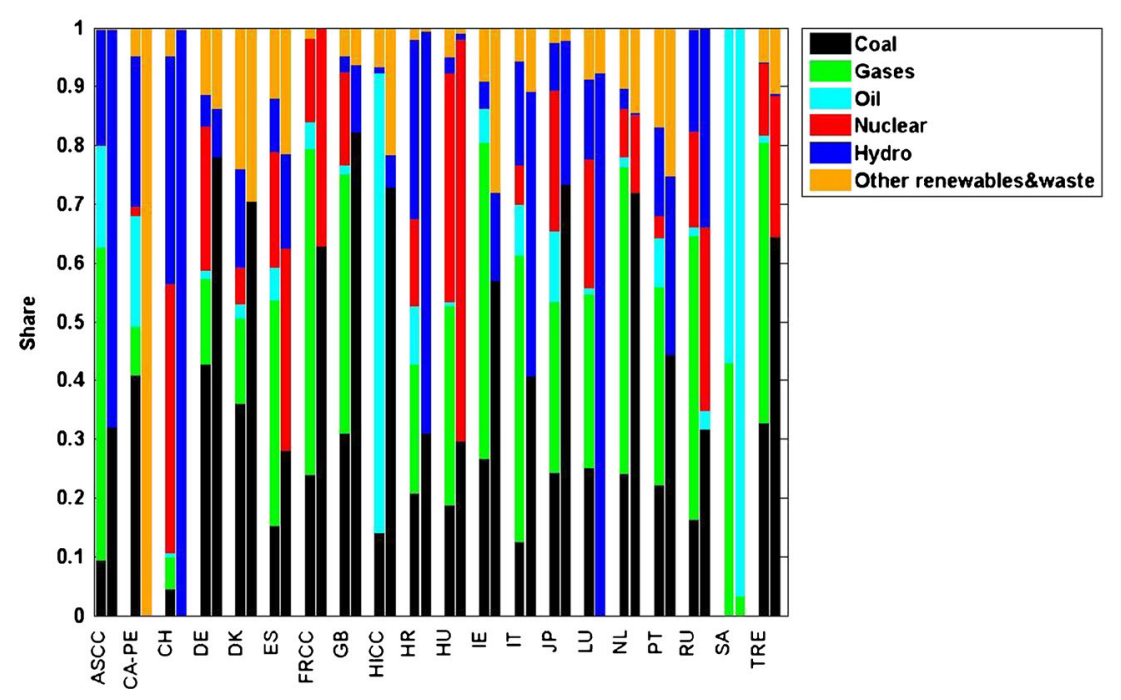


(DE in Fig. 6) consists of coal power as most important contributor, hydro and other renewables (wind power and photovoltaics). This roughly reflects the current trend in replacement/extension of generation capacities with coal as the most competitive fuel and wind and photovoltaics being subsidized.

\section{Conclusions}

This paper presents the electricity markets modelled in the ecoinvent database version 3.01. The geography-specific electricity production mixes and electricity markets (i.e. supply mixes) calculated according to the two different system models of the ecoinvent database ("allocation, default", i.e. attributional; and, "substitution, consequential, long-term") are presented and discussed. Production mixes and supply mixes have been determined for the 32 geographical regions already present in ecoinvent version 2.2 plus 39 additional geographic regions, resulting in 71 geographical regions representing $83 \%$ of global electricity production in 2008 . All countries contributing more than $1 \%$ of global electricity production have been modelled as specific electricity markets. It is shown that geography-specific differences between single markets in terms of generation technologies and fuel shares as well as the differences in the composition of the production mix and supply mix can be significant, whereas amounts of imported electricity and differences in fuel shares between production and supply mix are not necessarily correlated.

Worldwide electricity production still relies heavily on fossil fuels. Fossil fuels are the major energy resource used for electricity generation in the largest markets such as the USA, China, India and Japan, and in many others. Among the renewables, hydropower is the most important source, whereas wind and photovoltaics as well as other renewables play a minor role in the 2008 electricity mixes, despite of their partially impressive growth rates during the latest years. The importance of partitioning large countries into regional electricity markets is demonstrated based on Canada, where the electricity markets of the 13 provinces/territories show all extremes from $100 \%$ renewable generation to $100 \%$ fossil generation and from nearly $100 \%$ imports to zero imports. The associated environmental burdens will differ accordingly. In LCA case studies with processes which can be localized more precisely than on a country level, such regional electricity markets will contribute to a better representation of actual electricity use and its environmental burdens and hence, the LCA results will be more accurate. Therefore, it is important for ecoinvent as a background database to offer electricity supply data on a more regional level for large countries. The electricity markets in other large countries, mainly Australia, China, India, and Russia, should be partitioned in the future.
Due to the current limitations in the modelling of the consequential electricity markets, the users of the database are recommended to take care in using the current inventories of the consequential electricity markets, to adapt the inventory data and to create more appropriate consequential electricity markets according to more specific information concerning constrained/unconstrained power generation in specific geographical regions, if these electricity markets are supposed to play an important role in their use of the ecoinvent database models with substitution. More sophisticated inventory data for the consequential system model-including explicit consideration of country-specific strategies for future power generation - are envisaged to be implemented in the database in order to overcome the current limitations in this context.

Overall, representative, consistent and up-to-date LCI data of electricity supply are often among the determining factors concerning LCA results, and therefore, the extension of geography-specific inventory data for power supply in ecoinvent v3 contributes to increasing quality and reducing uncertainties in LCA studies worldwide.

Acknowledgments The authors express their gratitude to René Itten, Rolf Frischknecht and Matthias Stucki from treeze for the preparation of the report on production volumes in all required countries; and to Pablo Tirado and Pascal Lesage from CIRAIG, Canada, for supply of high quality inventory data for the individual Canadian provinces/territories.

\section{References}

Bousquin J, Gambeta E, Esterman M, Rothenberg S (2012) Life cycle assessment in the print industry. J Ind Ecol 16:S195-S205

Frischknecht R, Faist Emmenegger M, Bauer C, Dones R (2007) Strommix und Stromnetz. In: Sachbilanzen von Energiesystemen: Grundlagen für den ökologischen Vergleich von Energiesystemen und den Einbezug von Energiesystemen in Ökobilanzen für die Schweiz (Ed. Dones R.). ecoinvent report No. 6, v2.0. Paul Scherrer Institut, Villigen / Swiss Centre for Life Cycle Inventories, Duebendorf, Switzerland

Hawkins T, Gausen O, Strømman A (2012) Environmental impacts of hybrid and electric vehicles - a review. Int J Life Cycle Assess 17(8):997-1104

Heinonen J, Junnila S (2011) Case study on the carbon consumption of two metropolitan cities. Int J Life Cycle Assess 16(6):569-579

Hischier R, Baudin I (2010) LCA study of a plasma television device. Int J Life Cycle Assess 15(5):428-438

IEA, OECD (2010) Electricity Information 2010. International Energy Agency, Paris Cedex, France

IEA, OECD (2011) Electricity and heat generation. International Energy Agency (IEA), Paris Cedex (FR), Electricity information statistics (database), retreived from: http://www.oecd-ilibrary.org/energy/

IEA (2012) IEA Home - Statistics and Balances. International Energy Agency. http://www.iea.org/stats/defs/sources/coal.asp. Accessed 24.01.213

ISO (2006a) ISO 14040. Environmental management-life cycle assessment-prinicples and framework. International Organisation for Standardisation (ISO) 
ISO (2006b) ISO 14044. Environmental management - life cycle assessment - requirements and guidelines. International Organisation for Standardisation (ISO)

Itten R, Frischknecht R, Stucki M (2012) Life Cycle Inventories of Electricity Mixes and Grid. ESU-services Ltd., Uster, Switzerland

Kendall A, McPherson E (2012) A life cycle greenhouse gas inventory of a tree production system. Int J Life Cycle Assess 17(4):444-452

Lund H, Mathiesen B, Christensen P, Schmidt J (2010) Energy system analysis of marginal electricity supply in consequential LCA. Int J Life Cycle Assess 15(3):260-271

Mathiesen BV, Muenster M, Fruergaard T (2009) Uncertainties related to the identification of the marginal energy technology in consequential life cycle assessments. J Clean Prod 17(15):1331-1338

Ménard M, Dones R, Gantner U (1998) Strommix in Ökobilanzen: Auswirkungen der Strommodellwahl für Produkt- und BetriebsÖkobilanzen. PSI-Bericht No. 98-17. Paul Scherrer Institut, Villigen, Switzerland

Mendoza J-M, Oliver-Solà J, Gabarrell X, Josa A, Rieradevall J (2012) Life cycle assessment of granite application in sidewalks. Int J Life Cycle Assess 17(5):580-592

Milà i Canals L, Sim S, García-Suárez T, Neuer G, Herstein K, Kerr C, Rigarlsford G, King H (2011) Estimating the greenhouse gas footprint of Knorr. Int J Life Cycle Assess 16(1):50-58
Mohr N, Meijer A, Huijbregts M, Reijnders L (2009) Environmental impact of thin-film GaInP/GaAs and multicrystalline silicon solar modules produced with solar electricity. Int J Life Cycle Assess 14(3):225-235

PAS (2011) PAS 2050:2011. Specification for the assessment of the life cycle greenhouse gas emissions of goods and services. British Standards Institute. ICS code: 13.030.40, ISBN 9780580713828

Schmidt J, Thrane M, Merciai S, Dalgaard R (2011) Inventory of country specific electricity in LCA - Consequential and attributional scenarios. Methodology report v2. 2-0 LCA consultants, Aalborg http:// wwwlca-netcom/projects/electricity_in_lca

Teehan P, Kandlikar M (2012) Sources of Variation in Life Cycle Assessments of Desktop Computers. J Ind Ecol 16:S182-S194

Torrellas M, Antón A, López J, Baeza E, Parra J, Muñoz P, Montero J (2012) LCA of a tomato crop in a multi-tunnel greenhouse in Almeria. Int J Life Cycle Assess 17(7):863-875

Treyer K, Bauer C (2013) Life cycle inventories of electricity generation and power supply in version 3 of the ecoinvent database - part I: electricity generation. Int J Life Cycle Assess. doi:10.1007/s11367013-0665-2

Weidema BP, Bauer C, Hischier R, Mutel C, Nemecek T, Reinhard J, Vadenbo CO, Wernet G (2013) Overview and methodology. Data quality guideline for the ecoinvent database version 3. St. Gallen: The ecoinvent Centre 